K.P. Figueroa, MS

Hilary Coon, $\mathrm{PhD}$

Nieves Santos, MS

Luis Velazquez, MD,

$\mathrm{PhD}, \mathrm{DrSc}$

Luis Almaguer Mederos, $\mathrm{PhD}$

Stefan M. Pulst, MD,

Dr med

Correspondence to

Dr. Pulst:

stefan.pulst@hsc.utah.edu

\section{Genetic analysis of age at onset variation in spinocerebellar ataxia type 2 \\ OPEN}

\section{ABSTRACT}

Objective: To examine heritability of the residual variability of spinocerebellar ataxia type 2 (SCA2) age at onset (AO) after controlling for CAG repeat length.

Methods: From 1955 to 2001, dates of birth, CAG repeat lengths, AO, sex, familial inheritances, and clinical manifestations were collected for a large Cuban SCA2 cohort of 382 affected individuals, including 129 parent-child pairs and 69 sibships. Analyses were performed with logtransformed $A O$ in the GENMOD procedure to predict $A O$ using repeat length, taking into account family structure. Because all relationships were first degree, the model was implemented with an exchangeable correlation matrix. Familial correlations were estimated using the Pedigree Analysis Package to control for similarity due to genetic relatedness.

Results: For the entire sample, the mutant CAG repeat allele explained $69 \%$ of $A O$ variance. When adjusted for pedigree structure, this decreased to 50\%. Evidence for imprinting or sex-specific effects of the CAG repeat on $A O$ was not found. For the entire sample, we determined an upper bound for heritability of the residual variance of 33\% $(p=0.008)$. Heritability was higher in sibsib pairs, especially in female sib-sib pairs, than in parent-child pairs.

Conclusions: We established that a large proportion of AO variance in SCA2 was determined by genetic modifiers in addition to CAG repeat length. The genetic structure of heritability of the residual $A O$ variance was surprisingly similar to Huntington disease, suggesting the presence of recessive modifying alleles and possibly X-chromosome-linked modifiers. Neurol Genet 2017;3:e155; doi: 10.1212/NXG.0000000000000155

\section{GLOSSARY}

$\mathbf{A O}=$ age at onset; $\mathbf{F C}=$ father-child; $\mathbf{H D}=$ Huntington disease; $\mathbf{M C}=$ mother-child; $\mathbf{P A P}=$ Pedigree Analysis Package; $\mathbf{P C}=$ parent-child; poly $\mathbf{Q}=$ polyglutamine; $\mathbf{R L}=$ repeat length; $\mathbf{S C A} \mathbf{2}=$ spinocerebellar ataxia type $2 ; \mathbf{S N P}=$ single nucleotide polymorphism.

Ten human neurodegenerative diseases, including spinocerebellar ataxia type 2 (SCA2), are caused by expansions of a coding CAG repeat. These diseases are referred to as polyglutamine (polyQ) diseases. Common to all polyQ diseases is a decrease in age at onset $(\mathrm{AO})$ with increasing repeat lengths (RLs). The square of the correlation coefficient $\left(r^{2}\right)$ ranges from 0.5 to $0.8 .{ }^{1-4}$ Despite this correlation, there is great variation of $\mathrm{AO}$ within each repeat class. This suggests the existence of other factors influencing disease onset and progression. A study of the Venezuelan Huntington disease (HD) population estimated that about $37 \%$ of the residual $\mathrm{AO}$ variance was attributable to additive genetic effects. ${ }^{5}$ Analysis of a second, multinational HD sample determined that $56 \%$ of the residual $\mathrm{AO}$ variance was heritable and revealed suggestive evidence for genetic modifiers on 4p16, 6p21-23, and 6q24-26. ${ }^{6,7}$ In an analysis of 148 Cuban SCA2 patients in 57 sibships, we determined that about half of the residual $\mathrm{AO}$ variance was heritable. ${ }^{3}$

SCA2 is relatively rare worldwide but has a prevalence of 40/100,000 in the Northeastern part of Cuba. ${ }^{8}$ This founder population ${ }^{9}$ provides a resource for genetic studies similar to the

From the Department of Neurology (K.P.F., S.M.P.), Department of Psychiatry (H.C.), University of Utah, Salt Lake City; Department of Surgery (N.S.), University of Miami, FL; and Center for the Research and Rehabilitation of Hereditary Ataxias (L.V., L.A.M.), Holguin, Cuba.

Funding information and disclosures are provided at the end of the article. Go to Neurology.org/ng for full disclosure forms. The Article Processing Charge was funded by the authors.

This is an open access article distributed under the terms of the Creative Commons Attribution-NonCommercial-NoDerivatives License 4.0 (CC BY-NC-ND), which permits downloading and sharing the work provided it is properly cited. The work cannot be changed in any way or used commercially without permission from the journal. 
HD population in Venezuela. ${ }^{5}$ As in other polyQ diseases, the mutant SCA2 allele explains between 0.55 and 0.7 of the $\mathrm{AO}$ variance in SCA2. 3,10

We report an analysis of factors influencing AO in the Cuban SCA2 cohort. We determined sex and imprinting effects on RL and $\mathrm{AO}$, as well as familial correlations for parent-child (PC) and sibling pairs.

METHODS Standard protocol approvals, registrations, and patient consents. Informed consent was obtained, and studies were approved by review boards in Holguin and Utah.

A total of 382 patients were recruited from the SCA2 population in Holguin province, Cuba from 1955 to 2001. Dates of birth, CAG RLs, AO, sex familial inheritance, and clinical manifestations were collected.

Determination of AO. AO was defined as the first sign of ataxia, usually manifested by unsteadiness of gait. $\mathrm{AO}$ was determined by 1 interviewer (N.S.) using self-report and, whenever possible, report of other family members. Usually, individuals and family members recalled specific life stages at which function was impaired, such as ability to perform military service, ability to ride a bicycle, to carry a child, or to handle tools. AO was virtually always related to balance problems. Although muscle cramps are common in the Cuban SCA2 population, noncerebellar symptoms were not used to determine $\mathrm{AO}$ in this sample. Faulty estimation of $\mathrm{AO}$ in individuals would result in a reduced estimate of familiality and an increased estimate of nonshared environmental components and stochastic factors.

DNA was extracted from venous blood and amplified using established primer pairs. ${ }^{11}$ All samples were analyzed at CIRAH (Holguin) using conditions previously described and confirmed in our laboratory in the United States. ${ }^{11}$

Analyses were performed using SAS/STAT software (sas.com) with log-transformed AO. We used the GENMOD procedure to predict $\mathrm{AO}$ using $\mathrm{RL}$, taking into account family structure. GENMOD uses generalized estimating equations to account for the nonindependence among related individuals.

Sensitivity analysis was not performed to determine bias due to aspects of sampling. However, certain aspects of sensitivity analysis were performed by reanalysis of data using different constellations of relatives, parent-offspring and sib pairs. Because all relationships were first degree, the model was implemented with an exchangeable correlation matrix.

Significance of familial resemblance was estimated using the Pedigree Analysis Package (PAP). ${ }^{12}$ Familial correlations were estimated using the PAP to control for similarity due to genetic relatedness.

An upper bound of heritability was computed in SOLAR. ${ }^{13}$ SOLAR tests the likelihood of heritability due to multiple gene effects (a polygenic model) of AO after taking into account RL. The estimate is an upper bound of genetic effects because only first-degree relatives were in the study cohort, and familial similarity, which is used to estimate heritability, includes both genetic and shared family environmental factors. Heritability was computed on all available data, then using only siblings and using only PC pairs to determine the impact of these relationships on the estimates.

RESULTS For the analysis of residual variance and heritability, information from 326 SCA2 patients was used to identify 69 sibships and 129 PC pairs (figure 1). Table 1 provides descriptive characteristics for the total cohort and for several subcohorts described below. Also shown are correlations between $A O$ and CAG RL, both uncorrected and corrected for pedigree structure. The correlations were all highly significant $(p<0.001)$.

Subcohort 1: RL. When we restricted the analysis to 205 adult onset samples with an RL from 32 to 40 repeats, we found that the variance in $\mathrm{AO}$ explained by RL (as measured using the $R^{2}$ statistic from the

Figure 1 Age at onset and CAG repeat of 326 Cuban spinocerebellar ataxia type 2 patients

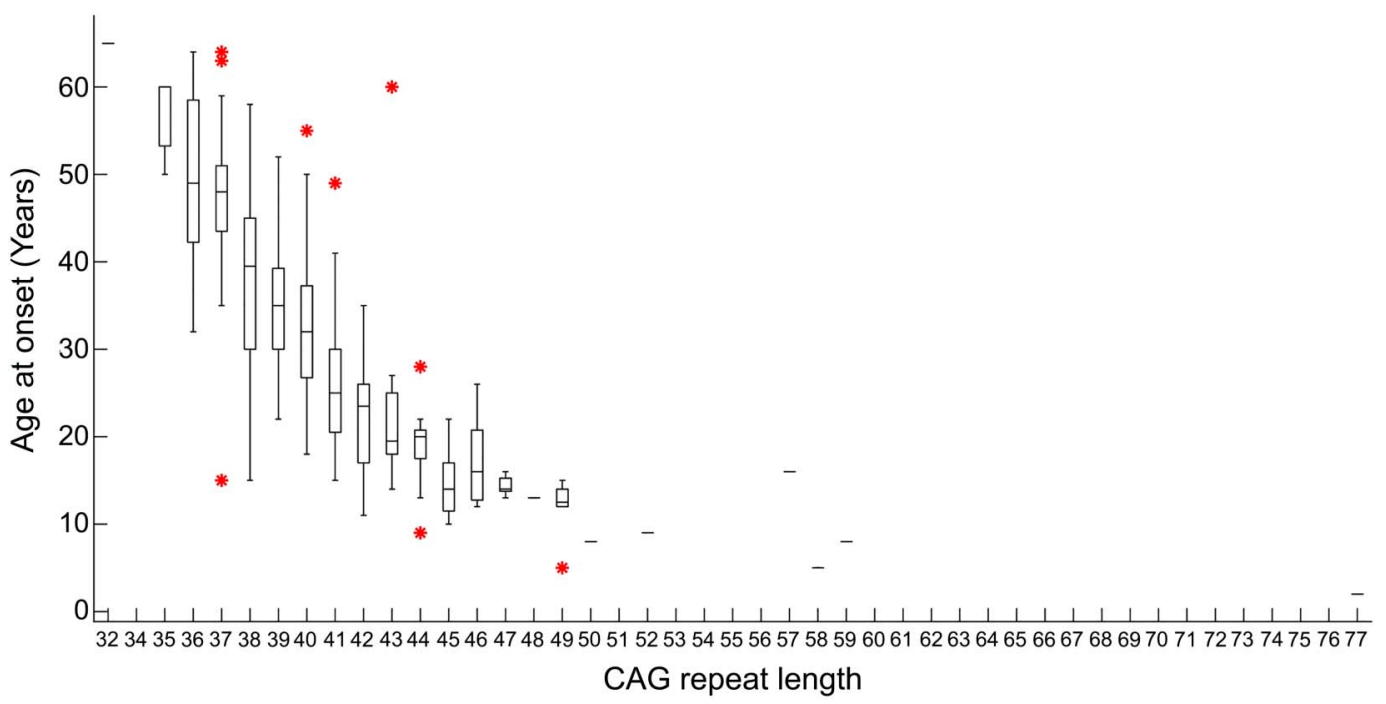

Box plot of age of disease onset and CAG repeat length of the expanded allele. Outliers for each CAG repeat were included in the analysis and are denoted in red asterisks. Bars denote interquartile range $\times 1.5$. 


\begin{tabular}{|llllll|}
\hline Table 1 & \multicolumn{7}{l|}{ Age at onset (AO) and CAG repeat correlations } \\
Cohort & N & $\begin{array}{l}\text { Mean } \\
\text { AO (SD) }\end{array}$ & $\begin{array}{l}\text { Mean repeat } \\
\text { length (SD) }\end{array}$ & $\begin{array}{l}R^{2} \text { due to repeat } \\
\text { (uncorrected) }\end{array}$ & $\begin{array}{l}R^{2} \text { due to repeat } \\
\text { (corrected) }^{\mathbf{a}}\end{array}$ \\
Total & 326 & $33(14)$ & $40(4)$ & 0.69 & 0.50 \\
Males & 173 & $33(15)$ & $40(5)$ & 0.69 & 0.56 \\
Females & 153 & $33(13)$ & $40(4)$ & 0.70 & 0.40 \\
CAG 32-40 & 205 & $40(11)$ & $38(2)$ & 0.38 & 0.22 \\
CAG 41-77 & 121 & $21(8)$ & $44(5)$ & 0.57 & 0.51 \\
Parents & 84 & $39(13)$ & $39(2)$ & 0.57 & 0.57 \\
Siblings & 183 & $33(14)$ & $40(3)$ & 0.62 & 0.23 \\
Paternal & 70 & $27(14)$ & $43(6)$ & 0.81 & 0.72 \\
Maternal & 78 & $28(12)$ & $41(4)$ & 0.58 & 0.34 \\
\hline
\end{tabular}

a Uncorrected/corrected for family structure.

model) was lowered; the $R^{2}$ uncorrected for family structure was 0.38 and 0.22 when corrected. For these RLs, the mutation explained slightly less than $25 \%$ of the variance when corrected for pedigree structure, indicating that genetic and environmental modifiers played a greater role in patients with the shorter and more common RLs.

Subcohort 2: Effect of birth year. Our birth year analysis is based on 382 affected subjects with known $\mathrm{AO}$ and year of birth. The overall distribution of $\mathrm{AO}$ had a mean of 31.22 years, SD of 16.38 , and a range of 2-65 years. We observed possible sampling bias resulting from a loss of subjects with longer repeats born before 1960 . These individuals had likely died before being examined, leading to an enrichment in this cohort of individuals with shorter pathologic repeats. This observation also implies that shorter pathologic repeats were underrepresented in the cohort born after 1960 because these subjects had not shown evidence of disease at the time of examination. This ascertainment bias may also produce unusual effects when looking at parental transmissions, as paternal transmissions tend to expand more than maternal.

There was no difference in the $\mathrm{AO}$ between males $(33.12 \pm 14.47)$ and females $(33.06 \pm 13.34)$. Mean CAG repeats for both sexes were virtually identical (males: $40.28 \pm 4.46$; females $40.12 \pm 3.71$ ). However, the corrected $R^{2}$ was higher for males than that for females, although this difference did not reach statistical significance (table 1).

We analyzed instability of the SCA2 repeat in 129 PC pairs. The repeat was more unstable in paternal vs maternal transmissions (figure 2, $\mathrm{A}$ and $\mathrm{B})$. On average, the repeat increased by $4.8 \pm 5.4$ units (range -1 to 36 units), when inherited from the father, but only by $1.6 \pm 2.0$ units (range -1 to 11 units), when inherited from the mother. Of the 6 expansions $>10$ units, 5 occurred when the repeat was passed through the father.
Important for genetic counseling, 2 of the large expansions occurred in parents with only 36 repeats.

In our adjusted analyses, sibship membership accounted for a substantial proportion of variance in AO $\left(F=1.73 ; p=0.001 ; R^{2}=0.23\right)$. The entries in the last column of table 1 therefore reflect variance explained by $\mathrm{AO}$ above and beyond variance explained by sibship membership. Note that the effect of repeat remained considerable in each of the models; although when RL was smaller, variance explained was reduced. Variance explained was also greater for paternal vs maternal transmissions, although this could be due to overall larger repeats observed in paternal transmissions.

We examined the effect of RL on AO in different male-female PC combinations. In the models run separately by maternal vs paternal inheritance, there was a significant sex effect and sex $\times$ repeat interaction. The cause of this sizable interaction may be the reduction in the differential prediction of repeat on $\mathrm{AO}$ in the mother-daughter pairs.

Effects of imprinting have not been studied in the dominant ataxias except for small samples that could only detect large effects. There was no difference in the mean repeat number or $\mathrm{AO}$ between paternal and maternal transmissions in our cohort of 326 subjects in whom the sex of the transmitting parent was known. The proportion of the variance in $\mathrm{AO}$ explained by the mutant allele was also similar in both patient groups. Thus, we did not find evidence for imprinting effects on $\mathrm{AO}$.

Familial correlation is defined as the correlation of a trait among family members, used as a tool to investigate genetic influences on a defined relationship. A value greater than zero implies genetic influence on that trait. We estimated familial correlations in 129 parent-offspring pairs. These results show an interesting difference in parentoffspring resemblance such that similarity is stronger in mother-child (MC) relationships (table 2). The test for significance of this difference was obtained in the PAP by comparing -2 times the natural $\log$ of the likelihood $(-2 \ln \mathrm{L})$ of the model estimating a single PC correlation (PC model) with $-2 \ln \mathrm{L}$ of the model allowing for different estimates for father-child and mother-child (FC, MC model). For all traits, the model allowing for different correlation estimates for MC vs FC pairs fits better than the model with a single PC estimate. For both unadjusted $\mathrm{AO}$ and RL, MC correlations were higher $(p=0.05$ and $p<0.0001$, respectively). A similar trend was observed for $\mathrm{AO}$ adjusted for repeat, but the difference did not reach significance. Freeing all parent-offspring relationships to test significance of sex of the child (mother-son, mother-daughter, father-son, and 

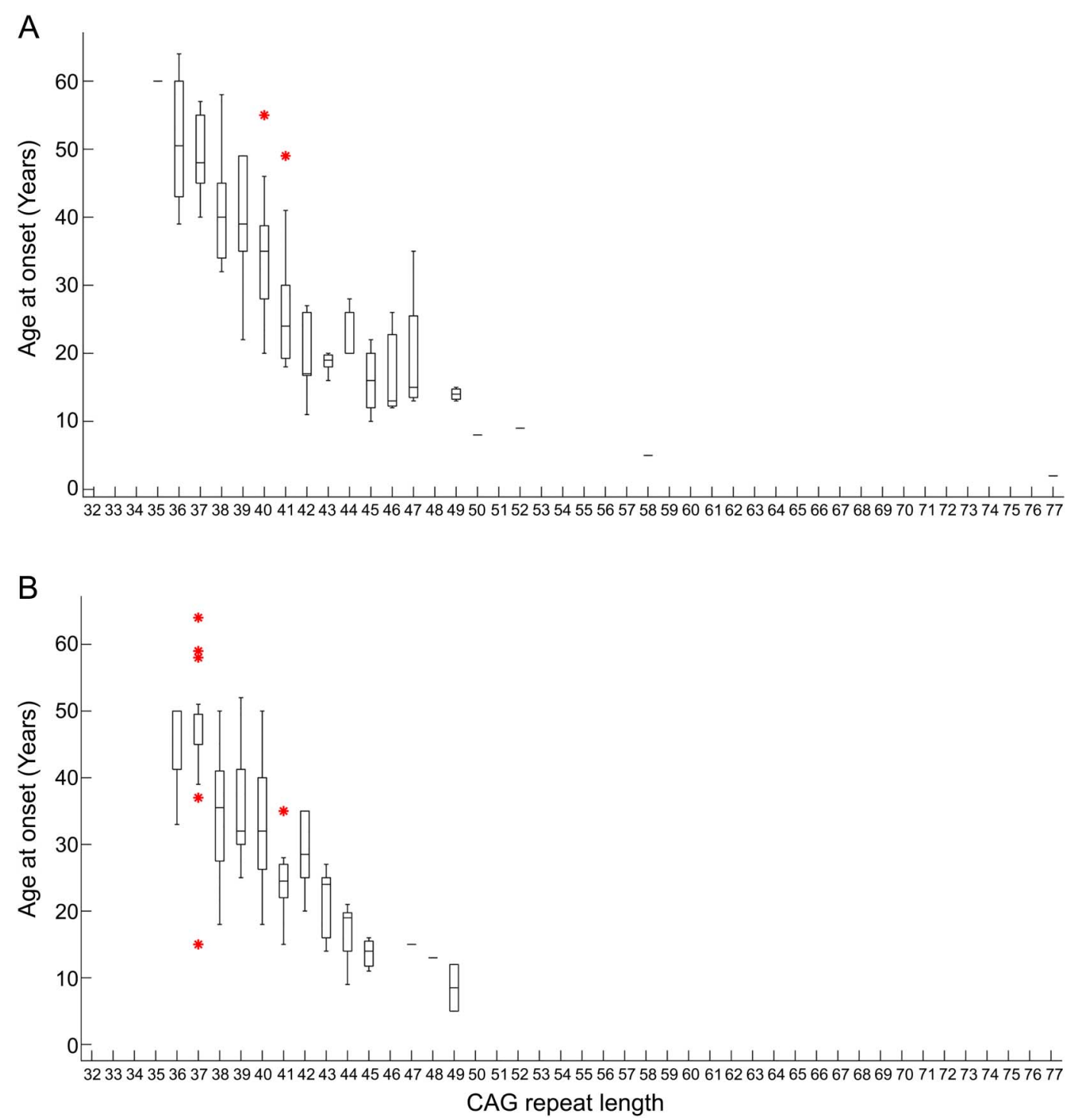

(A) Paternal. (B) Maternal. Box plot of age at onset and CAG repeat length of the expanded allele. Outliers for each CAG repeat denoted in red asterisks. Bars denote interquartile range $\times 1.5$. Note the higher instability of repeats seen in paternal vs maternal transmission.

father-daughter relationships) did not result in any further improvement in the fit of the model for any of the traits.

Heritability of residual AO variance. To estimate familiality or an upper bound for heritability of residual familial variance (adjusted AO), we used polygenic variance component analysis in SOLAR applied to AO data in the full cohort of 326 individuals. This set contained a total of 129 parent-offspring pairs. Most were in families with a single child, although 44 pairs were in families with 2 siblings, and 25 pairs were in families with 3 or more siblings. We determined an upper bound for heritability of the residual variance of $33 \%(p=0.008)$. As already suggested by our analyses of specific familial resemblance described above, heritability of the residual variance was higher when estimated only from siblings $(58 \%, p=0.001)$ than that from parent-offspring pairs $(10 \%, p=$ 0.02 ). The higher value in sib pairs may reflect the existence of recessive modifying alleles. Alternatively, siblings may share additional family environment over and above parent-offspring pairs.

Because lower heritability for male-male sibs was observed in HD, we analyzed for differences between male-male vs female-female sib pairs. Again, heritability estimates for both subgroups and female sibs showed more than twice the heritability of the residual than male sibs. However, the difference itself did not reach statistical significance.

Sibling correlation differences by sex were analyzed in more detail using PAP, similar to our PC 
Table 2 Parent-offspring correlations (estimated using the Pedigree Analysis Package)

\begin{tabular}{|c|c|c|c|c|c|c|}
\hline Relationship & $\mathbf{N}$ & $\begin{array}{l}\text { Correlation of } \\
\text { log (AO) } \\
\text { unadjusted (SE) }\end{array}$ & $\begin{array}{l}\text { Correlation of } \\
\text { repeat length (SE) }\end{array}$ & $\begin{array}{l}\text { Correlation of log (AO) } \\
\text { adjusted for repeat (SE) }\end{array}$ & $H D,{ }^{5} \mathrm{~N}$ & $\begin{array}{l}H^{5} \text { correlation for } \\
\text { residual } A O \text { (SE) }\end{array}$ \\
\hline Father-son & 35 & $0.32(0.12)$ & $0.02(0.13)$ & $0.07(0.17)$ & & NR \\
\hline Mother-son & 35 & $0.46(0.12)$ & $0.79(0.10)$ & $0.23(0.15)$ & & NR \\
\hline Father-daughter & 25 & $0.15(0.13)$ & $0.08(0.13)$ & $0.12(0.18)$ & & NR \\
\hline Mother-child (MC) & 69 & $0.47(0.12)$ & $0.77(0.08)$ & $0.14(0.13)$ & & NR \\
\hline Parent-child (PC) & 129 & $0.20(0.10)$ & $0.13(0.10)$ & $0.03(0.10)$ & 202 & $0.10(0.11)$ \\
\hline $\begin{array}{l}\chi^{2}([-2 \operatorname{lnL}(P C)]- \\
[-2 \operatorname{lnL}(\mathrm{FC}, \mathrm{MC})])^{\mathrm{a}}\end{array}$ & & $3.98(1 \mathrm{df}) ; p=0.05$ & 17.65 (1df); $p<0.0001$ & $1.94(1 d f) ; p=0.16$ & & \\
\hline
\end{tabular}

Abbreviations: $\mathrm{AO}=$ age at onset; $\mathrm{HD}=$ Huntington disease; $\mathrm{NR}=$ not reported.

a The difference between -2 times the natural log of the ratio of likelihoods of these nested models ([-2lnL (PC)] $-[-2 \operatorname{lnL}(F C=M C)])$ produces a $\chi^{2}$ test ( $d f=1$ ) of whether the FC correlation is significantly different from the MC correlation.

analyses as described above. These correlations are comparable with the intraclass correlations reported on this data set, although the PAP generates maximum likelihood estimates. PAP additionally allowed us to test for significant differences by sex (table 3). Male-male pairs showed lower correlations for both unadjusted $\mathrm{AO}(p=0.05)$ and adjusted $\mathrm{AO}(p<$ $0.0001)$. The adjusted $\mathrm{AO}$ correlations among sibling pairs were remarkably similar to those reported in a large Venezuelan pedigree. ${ }^{5}$

DISCUSSION In SCA2 and other polyQ diseases, the longer the length of the CAG repeat, the earlier the age of disease onset. ${ }^{2,14,15}$ Surprisingly, effects of sex, imprinting, and modifier alleles have received little attention in SCA2 or in other SCAs. Alleles of the retinoic acid-induced gene 1 were identified as AO modifiers for SCA2. ${ }^{16}$

We examined the relationship between CAG repeat and AO in the Cuban SCA2 founder population. The study of founder populations has certain inherent advantages, as they tend to be more homogenous both genetically and environmentally, which may facilitate genetic analysis. On the other hand, findings in founder populations may be difficult to generalize to other populations. It is unknown if the common founder haplotype is European, African, or Native American, and there is evidence of extensive population admixture in Cuba. ${ }^{17}$

The presence of founder alleles may explain why our prior evidence for variation in CACNAIA as a modifier of $\mathrm{AO}^{3}$ did not generalize to a European and US American population. ${ }^{18}$ Detailed comparisons can only be made with 2 studies of HD with large sample sizes. ${ }^{5,6}$

Despite the large sample size, our study was not population based. Therefore, it shares with previous studies inherent biases of referral for genetic testing by medical providers, self-referral in motivated families, and ascertainment bias based on inclusion of gene carriers who become affected first in a given family. Our cohort did not include asymptomatic gene carriers or individuals at risk for the disease.

In the Cuban SCA2 population, $69 \%$ of the observed variation on $\mathrm{AO}$ was explained by the

Table 3 Familial correlations of AO and CAG repeat

\begin{tabular}{|c|c|c|c|c|c|c|}
\hline Relationship & $\mathbf{N}$ & $\begin{array}{l}\text { Correlation of } \\
\log (A O) \text { unadjusted }\end{array}$ & $\begin{array}{l}\text { Correlation of } \\
\text { repeat length }\end{array}$ & $\begin{array}{l}\text { Correlation of log (AO) } \\
\text { adjusted for repeat }\end{array}$ & $H D,{ }^{5} \mathrm{~N}$ & $\begin{array}{l}\mathrm{HD}^{5} \text { correlation for } \\
\text { residual } \mathrm{AO} \text { (SE) }\end{array}$ \\
\hline Male-male sib pairs (MM) & 56 & $0.60(0.05)$ & $0.84(0.04)$ & $0.20(0.12)$ & 108 & $0.18(0.20)$ \\
\hline Female-female sib pairs (FF) & 38 & $0.76(0.04)$ & $0.75(0.06)$ & $0.52(0.13)$ & 113 & $0.49(0.13)$ \\
\hline Male-female sib pairs (MF) & 91 & $0.74(0.05)$ & $0.79(0.04)$ & $0.40(0.10)$ & 220 & $0.40(0.11)$ \\
\hline All sib pairs (sib-sib) & 185 & $0.71(0.05)$ & $0.79(0.03)$ & $0.33(0.09)$ & 441 & $0.40(0.09)$ \\
\hline $\begin{array}{l}\chi^{2}([-2 \operatorname{lnL}(\text { sib-sib)] }- \\
[-2 \operatorname{lnL}(\mathrm{MM}=\mathrm{MF}=\mathrm{FF})])^{\mathrm{a}}\end{array}$ & & $6.04(2 d f) ; p=0.05$ & $1.62(2 d f) ; p=0.45$ & $29.12(2 d f) ; p<0.0001$ & & \\
\hline
\end{tabular}

Abbreviations: $A O=$ age at onset; $H D=$ Huntington disease.

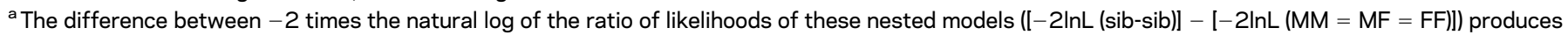
a $\chi^{2}$ test $(\mathrm{df}=2)$ of whether the sib correlations differ by sex. ${ }^{5}$ 
RL. Although this is in good agreement with other studies, ${ }^{1,2,10,14,19,20}$ it is difficult to perform precise comparisons, as most studies used a simple regression without taking pedigree structure into consideration.

Variability of AO in SCA1 individuals appeared to cluster within families, suggesting the presence of shared environmental and genetic factors on $\mathrm{AO} .^{21}$ In one study, the effect of the normal allele in SCA2 was examined and found to have little influence on AO. ${ }^{2}$ The normal allele in Cuban SCA2 is not highly variable; only 31 patients carried a 23 CAG ATXN2 allele preventing us from examining this effect.

The concept of familiality encompasses shared environmental and shared genetic factors and may be difficult to differentiate from heritability in human populations. In the strict sense, heritability denotes the proportion of phenotypic variance that can be attributed to additive genetic variance. Our estimate that $33 \%$ of the residual AO variance in SCA2 individuals was familial was lower than those of our previous analyses. However, this discrepancy was explained, when we examined residual heritability separately in sibling and PC pairs. An upper bound estimate of heritability as estimated using SOLAR was higher in siblings, and at $58 \%$, it was close to the previously reported value of 55\% using the coefficient of intraclass correlation in sibships to estimate heritability.

We can compare our analyses to 1 study of SCA $2^{10}$ and 2 studies in HD. ${ }^{5,6}$ In SCA2 pedigrees, the $\mathrm{CAG}$ repeat determined $73 \%$ of $\mathrm{AO}$ variance and by incorporating familial dependency, the repeat influence actually increased to $80 \% .^{10}$ In one study of $\mathrm{HD}$, the CAG repeat in the HD gene explained $67 \%$ of AO variance. ${ }^{6}$ When the size of the normal allele was taken into consideration, this value increased to $68 \%$. Heritability of the residual variance was $56 \%$.

An analysis of the large Venezuelan HD pedigree showed surprising similarities to our studies. ${ }^{5}$ Variance-components analysis was used to estimate the between and within sibling pair variances allowing for the computation of the sibling intraclass correlation. The estimated sibling correlation for the residual AO was 0.42 , leading to an upper estimate for heritability of $84 \%$. This value is higher than that of our SCA2 siblings, who only showed a correlation of 0.33 . Both studies found a much lower correlation for PC than sibling pairs, which was 0.10 in both studies. This may point to the presence of recessive modifying alleles but could also point to fewer shared environmental factors across generations than for siblings.

Analysis of the Venezuelan pedigree revealed another striking similarity with Cuban SCA2. Female-female sib pairs had much higher correlation than male-male sibs (table 3). This was noted in the Venezuelan pedigrees as well, ${ }^{5}$ but the authors were cautious in commenting on them, as the large standard errors associated with these estimates did not result in statistical significance. It is intriguing that our data not only show similar qualitative differences but display virtually identical correlation coefficients for sex effects in sibling pairs. Sex effects also extend to $\mathrm{PC}$ pairs, as MC pairs had higher correlations than FC pairs.

What model may explain the greatly reduced brother-brother correlations of $\mathrm{AO}$ after correction for CAG repeat size? Of note, imprinting does not explain the observations, as the SCA2 repeat has the same effect on $\mathrm{AO}$ in females and in males, as well as after passage through the paternal or maternal germline. Thus, one needs to search for mechanisms that largely act stochastically, affecting males only or at least preferentially. These could be related to endogenous male factors such as hormonal differences or to male-specific lifestyle choices such as smoking or alcohol use. Furthermore, males share X-chromosomes only $50 \%$ of the time, whereas females all receive the same $\mathrm{X}$ from the father and share the other one $50 \%$ of the time. Finally, the possibility remains that there is greater somatic instability in males, which would show as a stochastic variance component in our analyses.

We did not collect epidemiologic data to analyze whether the environment experienced by males was more variable than that for females. For example, if tobacco or alcohol use were important in SCA2 pathogenesis, and women were largely abstinent with highly variable use among men, this might explain reduced heritability in male siblings.

The nature of the recently identified modifiers for $\mathrm{AO}$ in $\mathrm{HD}$ is important with regard to this study. ${ }^{22}$ This study found connection between $\mathrm{AO}$ and several pathways subgrouped into 3 clusters by gene membership in the following: DNA repair, mitochondrial fission, and oxidoreductase activity. Several of the single nucleotide variants (single nucleotide polymorphisms [SNPs]) were replicated in separate cohorts of HD and SCA patients. ${ }^{23}$ Some of the SNPs were validated for SCA2 in particular. Although the 2 studies defined common SNPs and identified potentially common pathways related to DNA repair, the majority of the residual AO variance remained unexplained. ${ }^{23}$ This points to the potential presence of rare variation with large effects or to modifiers acting only in a specific setting of gene-environment interactions that is not shared across different cohorts. ${ }^{3}$

\section{AUTHOR CONTRIBUTIONS}

K.P. Figueroa: study concept and design, analysis, interpretation of data, and critical revision of manuscript for intellectual content. Dr. Coon: analysis and interpretation of data. Nieves Santos, Dr. Velazquez, and 
Dr. Mederos: acquisition of data. Dr. Pulst: study concept and design, analysis, interpretation of data, and critical revision of manuscript for intellectual content.

\section{ACKNOWLEDGMENT}

The authors thank their Cuban patients for participating in these investigations. This publication is dedicated to the memory of Carmen Warschaw, a great supporter of neurogenetics and neurology research.

\section{STUDY FUNDING}

This work was supported by grants from the NIH (R37 NS33123 to S.M.P., and R01 MH099134 and R01 MH094400 to H.C.), the National Ataxia Foundation (S.M.P.), and the Carmen and Louis Warschaw Endowment for Neurology (S.M.P.).

\section{DISCLOSURE}

K.P. Figueroa reports no disclosures. Dr. Coon has received research support from NIMH and the Simons Foundation. Nieves Santos, Dr. Velazquez, and Dr. Mederos report no disclosures. Dr. Pulst serves on the editorial boards of Journal of Cerebellum, NeuroMolecular Medicine, Continuum, Experimental Neurology, Neurogenetics, and Nature Clinical Practice Neurology and as Editor-in-Chief of Current Genomics and of Neurology ${ }^{\circledR}$ Genetics; and holds patents for the following: Nucleic acids encoding ataxin-2 binding proteins; Nucleic acid encoding Schwannomin-bindingproteins and products related thereto; Transgenic mouse expressing a polynucleotide encoding a human ataxin-2 polypeptide; Methods of detecting spinocerebellar ataxia-2 nucleic acids; Nucleic acid encoding spinocerebellar ataxia- 2 and products related thereto; Shwannomin-binding-proteins; and Compositions and methods for spinocerebellar ataxia. In addition, he receives publishing royalties from Churchill Livingston, AAN Press, Academic Press, and Oxford University Press; has served on the speakers bureau of Athena Diagnostics, Inc.; receives research support from NIH, Target ALS, National Ataxia Foundation, and ISIS Pharmaceuticals; has consulted for Ataxion Therapeutics; is a stockholder of Progenitor Life Sciences; has received license fee payments from Cedars-Sinai Medical Center; has given expert testimony for Hall \& Evans, LLC; and receives an honorarium from the AAN as the Editor of Neurology: Genetics. Go to Neurology.org/ng for full disclosure forms.

Received January 3, 2017. Accepted in final form April 3, 2017.

\section{REFERENCES}

1. van de Warrenburg BP, Sinke RJ, Verschuuren-Bemelmans CC, et al. Spinocerebellar ataxias in the Netherlands: prevalence and age at onset variance analysis. Neurology 2002;58: 702-708.

2. Cancel G, Durr A, Didierjean O, et al. Molecular and clinical correlations in spinocerebellar ataxia 2: a study of 32 families. Hum Mol Genet 1997;6:709-715.

3. Pulst SM, Santos N, Wang D, et al. Spinocerebellar ataxia type 2: polyQ repeat variation in the CACNA1A calcium channel modifies age of onset. Brain 2005;128:22972303.

4. van de Warrenburg BP, Sinke RJ, Kremer B. Recent advances in hereditary spinocerebellar ataxias. J Neuropathol Exp Neurol 2005;64:171-180.

5. Wexler NS, Lorimer J, Porter J, et al. Venezuelan kindreds reveal that genetic and environmental factors modulate Huntington's disease age of onset. Proc Natl Acad Sci USA 2004;101:3498-3503.

6. Djousse L, Knowlton B, Hayden $\mathrm{M}$, et al. Interaction of normal and expanded CAG repeat sizes influences age at onset of Huntington disease. Am J Med Genet A 2003; 119A:279-282.

7. Li JL, Hayden MR, Almqvist EW, et al. A genome scan for modifiers of age at onset in Huntington disease: the HD MAPS study. Am J Hum Genet 2003;73:682-687.

8. Velazquez Perez L, Cruz GS, Santos Falcon N, et al. Molecular epidemiology of spinocerebellar ataxias in Cuba: insights into SCA2 founder effect in Holguin. Neurosci Lett 2009;454:157-160.

9. Hernandez A, Magarino C, Gispert S, et al. Genetic mapping of the spinocerebellar ataxia 2 (SCA2) locus on chromosome 12q23-q24.1. Genomics 1995;25:433-435.

10. van de Warrenburg BP, Hendriks H, Durr A, et al. Age at onset variance analysis in spinocerebellar ataxias: a study in a Dutch-French cohort. Ann Neurol 2005;57:505-512.

11. Pulst SM, Nechiporuk A, Nechiporuk T, et al. Moderate expansion of a normally biallelic trinucleotide repeat in spinocerebellar ataxia type 2. Nat Genet 1996;14: 269-276.

12. Hasstedt S. jPAP: document-driven software for genetic analysis. Genet Epidemiol 2005;29:255.

13. Almasy L, Blangero J. Multipoint quantitative-trait linkage analysis in general pedigrees. Am J Hum Genet 1998;62: 1198-1211.

14. Geschwind DH, Perlman S, Figueroa CP, Treiman LJ, Pulst SM. The prevalence and wide clinical spectrum of the spinocerebellar ataxia type 2 trinucleotide repeat in patients with autosomal dominant cerebellar ataxia. Am J Hum Genet 1997;60:842-850.

15. Schols L, Gispert S, Vorgerd M, et al. Spinocerebellar ataxia type 2: genotype and phenotype in German kindreds. Arch Neurol 1997;54:1073-1080.

16. Hayes $S$, Turecki G, Brisebois $K$, et al. CAG repeat length in RAI1 is associated with age at onset variability in spinocerebellar ataxia type 2 (SCA2). Hum Mol Genet 2000; 9:1753-1758.

17. Mendizabal I, Sandoval K, Berniell-Lee G, et al. Genetic origin, admixture, and asymmetry in maternal and paternal human lineages in Cuba. BMC Evol Biol 2008;8:213.

18. Tezenas du Montcel S, Durr A, Bauer P, et al. Modulation of the age at onset in spinocerebellar ataxia by CAG tracts in various genes. Brain 2014;137:2444-2455.

19. Riess O, Laccone FA, Gispert S, et al. SCA2 trinucleotide expansion in German SCA patients. Neurogenetics 1997; 1:59-64.

20. Giuffrida S, Lanza S, Restivo DA, et al. Clinical and molecular analysis of 11 Sicilian SCA2 families: influence of gender on age at onset. Eur J Neurol 1999;6:301-307.

21. Ranum LP, Chung MY, Banfi S, et al. Molecular and clinical correlations in spinocerebellar ataxia type I: evidence for familial effects on the age at onset. Am J Hum Genet 1994;55:244-252.

22. Genetic Modifiers of Huntington's Disease Consortium. Identification of genetic factors that modify clinical onset of Huntington's disease. Cell 2015;162:516-526.

23. Bettencourt C, Hensman-Moss D, Flower M, et al. DNA repair pathways underlie a common genetic mechanism modulating onset in polyglutamine diseases. Ann Neurol 2016;79:983-990. 


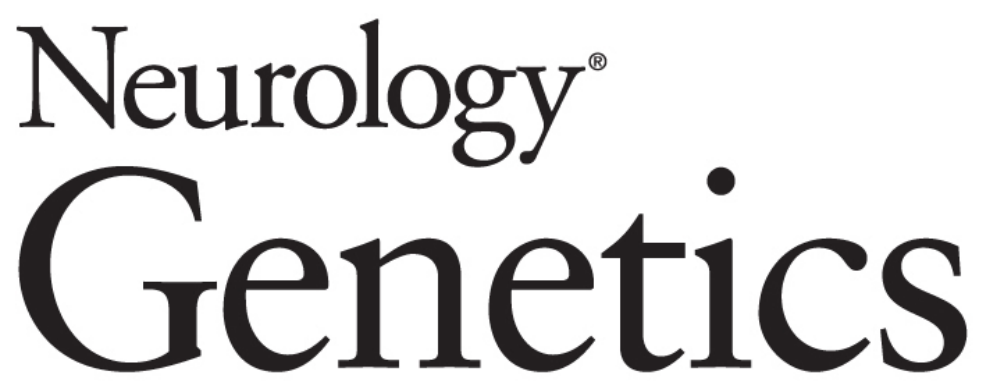

Genetic analysis of age at onset variation in spinocerebellar ataxia type 2 K.P. Figueroa, Hilary Coon, Nieves Santos, et al. Neurol Genet 2017;3;

DOI 10.1212/NXG.0000000000000155

This information is current as of May 15, 2017

Neurol Genet is an official journal of the American Academy of Neurology. Published since April 2015, it is an open-access, online-only, continuous publication journal. Copyright Copyright @ 2017 The Author(s). Published by Wolters Kluwer Health, Inc. on behalf of the American Academy of Neurology. All rights reserved. Online ISSN: 2376-7839.

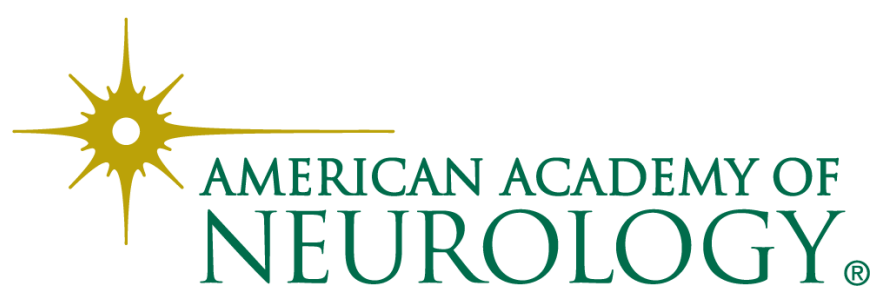




\section{Updated Information \& Services}

References

Citations

Subspecialty Collections

Permissions \& Licensing

Reprints including high resolution figures, can be found at: http://ng.neurology.org/content/3/3/e155.full.html

This article cites 23 articles, 1 of which you can access for free at: http://ng.neurology.org/content/3/3/e155.full.html\#\#ref-list-1

This article has been cited by 2 HighWire-hosted articles: http://ng.neurology.org/content/3/3/e155.full.html\#\#otherarticles

This article, along with others on similar topics, appears in the following collection(s):

Association studies in genetics

http://ng.neurology.org//cgi/collection/association_studies_in_genetics Cerebellum

http://ng.neurology.org//cgi/collection/cerebellum

Natural history studies (prognosis)

http://ng.neurology.org//cgi/collection/natural_history_studies_prognos is

Spinocerebellar ataxia

http://ng.neurology.org//cgi/collection/spinocerebellar_ataxia

Trinucleotide repeat diseases

http://ng.neurology.org//cgi/collection/trinucleotide_repeat_diseases

Information about reproducing this article in parts (figures,tables) or in its entirety can be found online at:

http://ng.neurology.org/misc/about.xhtml\#permissions

Information about ordering reprints can be found online:

http://ng.neurology.org/misc/addir.xhtml\#reprintsus

Neurol Genet is an official journal of the American Academy of Neurology. Published since April 2015, it is an open-access, online-only, continuous publication journal. Copyright Copyright ( 2017 The Author(s). Published by Wolters Kluwer Health, Inc. on behalf of the American Academy of Neurology. All rights reserved. Online ISSN: 2376-7839.

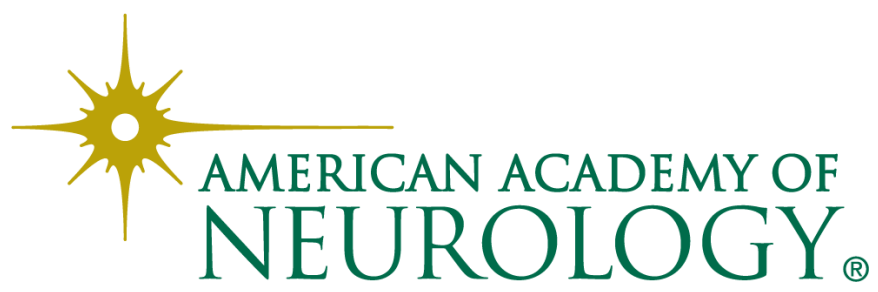

